\title{
REFLEXÕES SOBRE TRADUÇÃO NO DE FINIBUS DE CÍCERO E A REFUTAÇÃO DO PENSAMENTO ESTOICO
}

\author{
Sidney Calheiros de Lima* * DLCV/FFLCH/USP
}

RESUMO: Ambientado em uma vasta biblioteca, situada numa uilla recentemente herdada por um jovem aristocrata romano, o segundo diálogo do De finibus de Cícero (livros III e IV) comporta a tarefa de discutir em latim o pensamento moral dos antigos estoicos. No início da discussão, Cícero e Catão, o jovem, as personagens em cena, refletem sobre as estratégias que podem empregar para traduzir para o latim os conceitos forjados em grego por Zenão e Crisipo. Nosso objetivo é investigar o modo como a defesa de certo tipo de tradução filosófica, apresentada no início do livro III, pode servir à refutação da moral estoica empreendida pela personagem Cícero ao longo do livro IV, uma vez que se ajusta ao projeto filosófico do autor, que tem como meta a formação dos homens públicos romanos.

PALAVRAS-CHAVE: Filosofia helenística; estoicismo; Cícero; tradução.

\section{RÉFLEXIONS SUR LA TRADUCTION DANS LE DE FINIBUS DE CICÉRON ET LA RÉFUTATION DE LA PENSÉE STOÏCIENNE}

\begin{abstract}
La scène du deuxième dialogue du De finibus se développe dans une riche bibliothèque, qui se trouve dans une uilla récemment héritée par un jeune homme de l'aristocratie Romaine. Les interlocuteurs, Cicéron et Caton, le jeune, se proposent la tâche de discuter en latin de la pensée éthique des anciens stoïciens. C'est ainsi qu'ils se mettent à réfléchir sur les stratégies dont ils peuvent se servir pour traduire les concepts utilisés par Zénon et Chrysippe. Nous essayerons d'investiguer comment la apologie d'une façon de traduire la pensée
\end{abstract}


1. LIMA, S. C. "Cícero e a obra filosófica em latim como munus rei publicae". Nuntius Antiquus, v. V, p. 92-110, jul. 2010 . philosophique, qui est faite au début du troisième livre, peut servir à la réfutation de la morale stoïcienne, conduite par le personnage Cicéron dans le quatrième livre: cette façon de traduire s'ajuste au projet philosophique de l'auteur, dont le but déclaré est la formation des hommes politiques Romains.

KEYWORDS: Philosophie hellénistique; stö̈cisme; Cicéron; traduction.

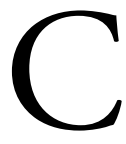

omposto em 45 a. C., o De finibus bonorum et malorum se insere num amplo projeto empreendido por Cícero, cujo desenvolvimento se torna mais intenso nos últimos anos de sua vida, o qual visava trazer ao latim a filosofia grega. Em outra ocasião, pretendemos mostrar que tal projeto é apresentado pelo autor como um munus rei publicae, isto é, como um serviço que ele presta à sua cidade, à causa comum, aos seus concidadãos. ${ }^{1}$

No contexto da ditadura de César e do período de incertezas que se seguiu ao assassinato do tirano - é dessa época boa parte da produção filosófica de Cícero -, declarar tal apego à res publica, como faz em muitos de seus prefácios, não serve apenas, como pensam alguns, para angariar a simpatia de um segmento considerável da sociedade romana ou a elevar o status de seu otium. Tem essa finalidade também, mas, parece-nos, é antes de qualquer outra coisa, a clara manifestação de um posicionamento político, o qual informa boa parte das reflexôes filosóficas do autor. A filosofia, como ars uiuendi, deve estar a serviço da vida que é própria do homem, a vida em sociedade. Em nossa opinião, a atividade filosófica de Cícero não pode ser bem compreendida, caso se negligencie a função política de que ela deliberadamente se reveste.

Para tratar especificamente do De finibus, obra nem sempre conhecida do grande público, talvez valha a pena tomar uma declaração dada pela persona do autor no prefácio geral à obra e, a partir dela, apresentar algumas palavras a título de introdução.

Ora, o que se deve de tal modo buscar na vida senão o que se busca tanto na filosofia em seu todo, quanto nestes livros sobretudo: qual é o fim, o que é extremo, o que é último, para 
onde se deve reportar todo desígnio de viver bem e agir com retidão; o que a natureza persegue como aquilo que é supremo dentre as coisas a serem buscadas e o que ela evita como o extremo dos males? E uma vez que a respeito desse assunto há entre os mais eruditos enorme discordância, quem consideraria impróprio do prestígio que a mim cada qual atribui investigar o que é o melhor e o mais verdadeiro em todas as ocupaçôes da vida? ${ }^{2}$

Deve-se dizer que o conceito de finis, ou antes, те́̉os, remonta ao pensamento de Aristoteles, ${ }^{3}$ do qual não pretendemos tratar aqui. Por motivos práticos, basta-nos observar que, ao anunciar a res do tratado, Cícero expóe de modo claro o conceito, traduzindo-o para o latim. Trata-se daquele fim último que motiva todas as nossas ações. Em um esforço para tornar sua tradução mais clara, ${ }^{4}$ o autor apõe a finis os termos extremum e ultimum: trata-se do bem que ocupa a última posição - a mais importante, deve-se dizer - na série de bens que buscamos quando agimos: o bem último ou sumo bem.

Quanto ao método que será utilizado ao longo da investigação, ele se faz necessário diante da constatação da enorme dissensio que existe entre os mais eruditos. ${ }^{5}$ Se cada um afirma uma coisa, parece apropriado investigar a questão por meio do confronto entre discursos contraditórios, com vistas a alcançar o finis mais próximo da verdade. Tal procedimento, também indicado no trecho citado do prefácio do De finibus, é uma referência clara ao método da Nova Academia e a sua busca pelo probabile. ${ }^{6}$

Ao método se associa, além disso, a organização do tratado, último ponto de que trato nesta breve introdução. ${ }^{7}$ São três diálogos, cada um tratando da solução proposta para o finis por uma das mais importantes correntes filosóficas do período: o epicurismo, o estoicismo e a tradição acadêmico-peripatética. Cada um dos diálogos é ambientado em lugar e tempo distintos dos demais. Em cada cena, uma personagem (dois deles são mártires da república) representa o patronus de uma corrente filosófica. Depois de cada exposição, uma personagem que leva o nome Cícero intervém como refutador das teses apresentadas. Além do tema comum, confere unidade ao conjunto a persona do autor, que, falando em seu próprio nome, introduz, em três
2. De fin., I, 11: Quid est enim in uita tantopere quaerendum quam cum omnia in philosophia, tum id quod his libris quaeritur, qui sit finis, quid extremum, quid ultimum, quo sint omnia bene viuendi recteque faciendi consilia referenda, quid sequatur natura ut summum ex rebus expetendis, quid fugiat ut extremum malorum? Qua de re cum sit inter doctissimos summa dissensio, quis alienum putet eius esse dignitatis quam mihi quisque tribuat quid in omni munere uitae optimum et uerissimum sit exquirere?

3. Aristóteles, Ética a Nicômaco, 1094a18-22.

É bem verdade que a discussão moral fundamentada em uma questão acerca da finalidade da ação é algo que já se encontra em Platão. No Górgias, quando discute com Polo, Sócrates se serve da expressão oû

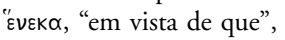
quando pergunta a Polo se o homem, quando faz algo, deseja aquilo mesmo que faz, ou outra coisa a que visa quando realiza a ação (Platão, Górgias 467d).

Veja-se também a reflexão de Dodds a respeito da questão em sua edição do diálogo mencionado (Dodds, 1990, p. 235237). O conceito de té $\lambda \circ$ os, como nos o conhecemos, no entanto, parece ter sido formulado por Aristóteles.

4. Cícero se mostra bem consciente de que traz aos romanos e à língua latina uma matéria nova, ainda não tratada nesse idioma. Mostra-se consciente também das dificuldades que tal empresa poderia lhe trazer. Cf. De fin., I, 1. 
5. Mais do que "sábio", o adjetivo doctus (Cícero utiliza o superlativo doctissimi) indica a condição de quem se dedicou ao estudo de uma doctrina.

Muito embora, no contexto da filosofia helenística, o estudo da doctrina pretenda redundar na formação um homem apto a agir de modo adequado, um sapiens, a raiz do verbo doceo nos remete ao ensino, ou seja, àquilo que é antes do âmbito da teoria.

6. Mesmo que os termos optimum e uerissimum pareçam conferir um caráter absoluto à solução, segundo pensamos (e a leitura total do tratado sugere exatamente isso), a ênfase está não propriamente na descoberta do que seja optimum e uerissimum em tudo aquilo a que nos aplicamos, mas, na verdade, na atividade de exquirere, de investigar, de discutir, por meio do exame das opiniōes divergentes dos mais eminentes filósofos.

7. A esse respeito, uma interessante declaração é dada em uma carta endereçada a Ático, datada de junho de 45 a. C., Ad Att., XIII, 19, 4: "Por outro lado, o que escrevi nestes últimos tempos tem um modo aristotélico, em que, de tal forma é introduzido o diálogo entre os demais, que nas mãos dele próprio esteja o papel principal. Dessa forma, compus cinco livros Sobre os fins, de modo que o que é de Epicuro eu confiasse a Lúcio Torquato, o que é dos estoicos, a Marco Catão, o dos

peripatéticos, a Marco Pisão" / Quae autem his prefácios, cada um dos diálogos, em uma conversação que se estabelece com o destinatário do tratado: Marco Júnio Bruto.

No segundo diálogo, o diálogo estoico, que nos interessa aqui, o interlocutor é Catão, o jovem, que, na época da composição, já havia cometido o célebre suicídio em Útica.

Ao introduzir o diálogo, o autor nos alerta para a dificuldade de confiar ao latim a complexa doutrina do Pórtico. Preocupado com tornar acessível o pensamento grego a seus concidadãos, Cícero prevê e justifica a introdução de palavras pouco usuais e mesmo novas em seu discurso. Toda arte tem seu jargão. Uma arte que se estabelece, além disso, terá de se servir de uma série de palavras novas, para dar conta das realidades, também novas, com que pretende lidar. ${ }^{8} \mathrm{Na}$ Grécia, o jargão filosófico, introduzido há já algum tempo, tornou-se, em certa medida, usual. Em Roma - defende o autor -, o estabelecimento do vocabulário filosófico se dá agora. Por vezes, na mimese forjada por Cícero, é como se nós, leitores, surpreendêssemos as personagens no processo mesmo de criação do jargão filosófico latino. Mas a linguagem sutil dos estoicos espinhosa até mesmo para os já versados em filosofia - traz uma dificuldade extra: "Dentre todos os filósofos, os estoicos foram os que mais inovaram e Zenão, primeiro dentre eles, não foi tanto um inventor de conceitos quanto de novas palavras".?

É desse modo que, antes mesmo de introduzir a cena, a persona do autor antecipa um dos principais argumentos que vai usar na refutação dos estoicos: a linguagem desses filósofos contém algo de vicioso. Ela é especialmente difícil porque seu fundador - na visão de Cícero - mais do que introduzir nova matéria, introduziu nova terminologia à matéria filosófica já existente.

Interessante notar, por outro lado, que o diálogo em que essa espinhosa doutrina é discutida contenha elementos dramáticos bastante particulares, se comparados aos que compõem as outras cenas, e que parecem bem ajustados à matéria tratada. Matizam a discussão. Não precisamos lembrar aqui a importância conferida por Cícero à representação cênica em seus diálogos. Mesmo se 
introduzidas de modo conciso - o que poderia fazer supor certa negligência -, as cenas são bem cuidadas e ajudam a dar significado às discussões que são nelas representadas. Há uma grande quantidade de testemunhos na correspondência do autor com Ático e com Quinto que dão conta do zelo do autor, das pesquisas a que se dedicava no momento de composição de uma cena, de uma personagem. ${ }^{10}$ No De finibus III, as cortinas se abrem assim:

Pois bem, como estivesse em minha quinta de Túsculo e quisesse me servir de certos livros da biblioteca do pequeno Luculo, fui até sua quinta a fim de que eu próprio os retirasse, como de costume. Lá chegando, vi Marco Catão, que eu não sabia que ali se encontrava, sentado no interior da biblioteca, envolto em uma profusão de livros estoicos. De fato, havia nele, como tu sabes, uma avidez pela leitura e ele não conseguia se saciar, visto que, nem mesmo temendo uma repreensão descabida do vulgo, até mesmo na Cúria, muitas vezes, costumava ficar lendo, até que se reunisse o senado, sem nada subtrair de sua atenção às questôes públicas. Quanto mais nessa ocasião, absolutamente livre de obrigaçôes e na mais extrema abundância, parecia como que se empanturrar dos livros, se tal expressão se deve usar para tão ilustre atividade. ${ }^{11}$

Com a cena, o autor póe em foco uma das grandes preocupaçōes de sua obra filosófica, à qual nos referimos no início da exposição: a educação dos jovens romanos. Explico: o jovem Luculo, um puer, $^{12}$ filho do indivíduo que dá nome a um dos livros da primeira versão da Academica de Cícero, ${ }^{13}$ tornara-se órfão na época da cena representada $\left(52\right.$ a. C.). ${ }^{14}$ $\mathrm{O}$ texto indica que sua tutela legal cabia a Catão. Mas, por conta dos laços de amizade que uniam Luculo, o pai da criança, e Cícero, a personagem que representa o autor diz sentir-se igualmente responsável pelo menino e enceta uma amistosa discussão acerca da educação do jovem aristocrata e da gestão de seu tão valioso bem: a vasta biblioteca. O debate acerca da moral estoica, introduzido a seguir, vem enquadrado, portanto, pela preocupação pedagógica.

Alguns estudiosos já notaram que, nos diálogos ciceronianos, as uillae desempenham uma função fundamental. ${ }^{15}$ Elas demarcam o espaço próprio do otium, condição necessária para que as personagens, que representam temporibus scripsi

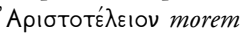

habent, in quo ita sermo

inducitur ceterorum ut

penes ipsum sit principatus.

Ita confeci quinque libros

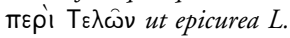

Torquato, stoica $M$.

Catoni, Пврıтотптıка̀ $M$.

Pisoni darem.

8. De fin., III, 3-4: “Dos estoicos, por outro lado, tu não ignoras quão sutil, ou melhor, espinhosa, é a forma de argumentar, e isso não só para os gregos, mas ainda mais para nós, que devemos mesmo criar palavras e atribuir a coisas novas termos novos. Algo de que ninguém que tenha recebido alguma instrução vai se admirar, certamente, ao refletir, é que em toda arte cujo uso não seja comum a todos grande é a novidade dos termos, quando se estejam estabelecendo palavras para designar aquelas coisas sobre as quais versa toda e qualquer arte.

Desse modo, tanto os

dialéticos quanto os físicos servem-se de palavras tais, que não são conhecidas da própria Grécia; já os geômetras, os músicos e mesmo os gramáticos falam de um modo que lhes é particular. Até as Artes dos retores, que são completamente voltadas para o fórum e para o povo, no âmbito do ensino, porém, utilizam palavras privadas, por assim dizer, e que lhes são próprias" I Stoicorum autem non ignoras quam sit subtile uel spinosum potius disserendi genus, idque cum Graecis tum magis nobis, quibus etiam uerba parienda sunt 
inponendaque noua rebus nouis nomina. quod quidem nemo mediocriter doctus mirabitur cogitans in omni arte, cuius usus uulgaris communisque non sit, multam nouitatem nominum esse, cum constituantur earum rerum uocabula, quae in quaque arte uersentur. itaque et dialectici et physici uerbis utuntur iis, quae ipsi Graeciae nota non sint, geometrae uero et musici, grammatici etiam more quodam loquuntur suo. ipsae rhetorum artes, quae sunt totae forenses atque populares, uerbis tamen in docendo quasi priuatis utuntur ac suis.

9. De fin., III, 5: Ex omnibus philosophis Stoici plurima nouauerunt, Zenoque, eorum princeps, non tam rerum inuentor fuit quam uerborum nouorum.

10. Mencionamos dois textos que analisam de modo cuidadoso partes da correspondência do autor que lidam com a composição de obras filosóficas. Um é o livro de Michel Ruch, Les préambules dans les oeuvres philosophiques de Cicéron essai sur la genèse et l'art $d u$ dialogue, de 1958. O outro, um artigo de Miriam Griffin, que trata mais especificamente do interessante caso das diferentes versōes dos Livros Acadêmicos: "The composition of the Academica: motives and versions", de 1997. Ambos os textos são citados nas Referências bibliográficas. homens públicos romanos, estando desobrigados dos assuntos relacionados à gestão da cidade, possam se consagrar às discussões abstratas da filosofia. É ao se referir à personagem de seu interlocutor, Catão, que Cícero chama atenção para isso (cf. quo magis jet in summo otio). Mas a densa e técnica disputatio acerca da filosofia moral estoica, doutrina de terminologia espinhosa, desenvolve-se em um lugar privilegiado da rica uilla Luculli: a biblioteca. Outros diálogos ocorrem ao ar livre, em um jardim, à sombra amena de uma árvore, ou durante uma agradável caminhada vespertina. ${ }^{16}$ Aqui, o espaço, próprio da dedicação ao estudo, e à leitura, acena para a sutileza da discussão. Mesmo a atitude dos interlocutores é especial: vão discutir sentados, cercados por livros que poderiam consultar. O próprio encontro se dá por conta de uma necessidade de Cícero: consultar certos livros. Mais adiante, saberemos que se trata de textos ligados à tradição aristotélica (cf. commentarios quosdam, inquam, Aristotelios, De fin., III, 10). Há algo na cena, porém, que chama ainda mais a atenção. Ao introduzir nela "o divino e singular Catão", Cícero habilmente aponta a avidez (deve-se notar, uma paixão!) de seu colega pela leitura e o modo como, em ocasiōes públicas, no Senado, encontrava-se absorto, tomado pela leitura (antes da sessão, que fique claro! ${ }^{17}$ ). Mais que isso, interessa ressaltar o verbo utilizado para descrever a leitura solitária de Catão na vasta biblioteca: ele "parecia como que se empanturrar dos livros (quase helluari)", diz o narrador, para logo fazer a ressalva: "se tal expressão se deve usar para tão ilustre atividade". Hutchinson, ${ }^{18}$ um antigo comentador do texto, adverte: o verbo é próprio da comédia. Não é anódina, a meu ver, a maneira como é introduzido o patrono desta doutrina que defende a extirpação das paixóes e que alega, como se sabe, haver um só e mesmo peso para todas as faltas. Mesmo que sutilmente, Cícero aponta excessos no modo de vida do singular Catão. ${ }^{19}$

A menção aos livros que cada qual foi buscar na vasta biblioteca abre caminho para uma urbana conversa acerca das inclinações filosóficas de cada um. Cicero, acadêmico, quis consultar textos da escola de Aristóteles, a qual, para ele, não é outra coisa senão acadêmicos discutindo em outro espaço, o Liceu. Catão, como já vimos, está envolto em livros 
estoicos. Cícero lança mão de um princípio do Pórtico (que reza que apenas o que é reto, ou honroso, é bom) e tenta mostrar como a adoção de tal princípio resulta em posicionamento idêntico ao de filósofos como Pirro e Aríston, para os quais todas as coisas, com exceção da virtude, seriam completamente indiferentes. É o ensejo para que Catão proponha uma exposição da real doutrina dos estoicos, a qual, segundo ele, embora reconheça que só a virtude é um bem, e que só a torpeza é um mal, teria condições de valorar e de distinguir tudo o que se encontra entre esta e aquela. Impõe-se à exposição de Catão, no entanto, a dificuldade de tratar da terminologia estoica em latim, já referida pelo autor no prefácio. É quando as personagens refletem, então, sobre as estratégias de tradução:

Vamos tentar, então - disse ele -, mesmo que o sistema dos estoicos tenha algo de muito difícil e obscuro. Pois, uma vez que na língua grega, outrora, estes mesmos termos aplicados a coisas novas pareciam novidades, termos que agora o uso continuado tornou correntes, o que consideras que vai acontecer em latim?

Isso, ao menos, não apresenta a menor dificuldade - disse eu. Pois se foi permitido a Zenão, porque tivesse inventado alguma coisa inusitada, atribuir a essa coisa um nome também inaudito, por que não seria permitido a Catão? Nem será forçoso, todavia, verter palavra por palavra, ${ }^{20}$ como costumam os tradutores sem arte, ${ }^{21}$ quando houver uma palavra mais usual que declare o mesmo. Quanto a mim, costumo até mesmo, se de outro modo não posso, expressar com muitas palavras aquilo que era expresso, em grego, com uma só. E, todavia, julgo que se nos deve conceder utilizarmos palavra grega, no caso de não se apresentar uma latina, e que isso não se conceda mais para 'ephippia' e 'acratophora' do que para 'proegmena' e 'apoproegmena'; muito embora quanto a estas últimas, será possível dizer, corretamente, 'preferíveis' e 'rejeitáveis'.

Fazes bem - disse ele - em me ajudar. E dentre essas palavras ao menos, que acabas de mencionar, vou utilizar de preferência as latinas; com relação a outras, tu virás me acudir, se me vires hesitante. $^{22}$

A fala de Cícero se inicia com uma defesa do uso de neologismos, a qual retoma a fala de Catão. $\mathrm{Na}$ exposição da ratio dos estoicos, é aceitável a palavra nova, uma vez que se trata de expor em latim um pensamento filosófico que,
11. De fin., III, 7: Nam

in Tusculano cum essem uellemque e bibliotheca pueri Luculli quibusdam libris uti, ueni in eius uillam, ut eos ipse, ut solebam, depromerem. quo cum uenissem, M. Catonem, quem ibi esse nescieram, uidi in bibliotheca sedentem multis circumfusum Stoicorum libris. erat enim, ut scis, in eo auiditas legendi, nec satiari poterat, quippe qui ne reprehensionem quidem uulgi inanem reformidans in ipsa curia soleret legere saepe, dum senatus cogeretur, nibil operae rei publicae detrahens. quo magis tum in summo otio maximaque copia quasi helluari libris, si hoc uerbo in tam clara re utendum est, uidebatur.

12. Cabe dizer que o jovem Luculo viria a morrer em 42 a. C., na batalha de Filipos, cidade da Macedônia, na qual Bruto e Cássio, principais lideranças dos republicanos na épica, e antes envolvidos no assassinato de Júlio César em 44 a. C., foram derrotados e mortos pelas forças dos triúnviros, Lépido, Marco Antônio e Otávio César. Ou seja, ao lado de Catão e de Torquato (o expositor do epicurismo no primeiro diálogo) é mais um mártir da República.

13. Lúcio Licínio Luculo, que foi cônsul em 74 a. C. Tendo alcançado também algum êxito militar (iniciou, por exemplo, a campanha contra Mitridates e Trigane, que foi, entretanto, concluída vitoriosamente por Pompeu), retirou-se, nos últimos anos de sua vida, em sua villa em Túsculo, 
reputada pelo luxo e refinamento e por uma excelente biblioteca.

14. Data que podemos determinar por conta de uma alusão, feita no início

do livro IV, a uma lei, recentemente promulgada por Pompeu, que redefinia

o tempo de duração de um debate jurídico. Cf. De finibus, IV, 1.

15. É o caso de autores como Wright (1991, p. 118), Ruch (1958, p. 23-32), dentre outros.

16. É célebre a cena do $D e$ oratore, cuja discussão se desenvolve sob a sombra de um plátano na villa de Crasso, coisa que faz com que os interlocutores se lembrem da cena do Fedro de Platão (cf. De oratore, I, 28). O diálogo representado no livro V do De finibus, por outro lado, se inicia com uma caminhada vespertina em direção ao sítio da Academia de

Platão, em Atenas. Já o De diuinatione constitui um caso interessante: no primeiro livro, que contém a exposição de Quinto sobre a adivinhação (em que ele defende teses estoicas, mas sobretudo elenca as diversas práticas divinatórias conhecidas), os interlocutores discutem ao longo de uma caminhada pelo Lycaeum da quinta de Cícero em Túsculo (cf. De diu., I, 8). No segundo livro, em que Cícero procede a uma refutação sistemática do discurso de Quinto, a qual é apoiada na tradição neoacadêmica, a discussão se dá dentro da biblioteca do Liceu (cf.

De diu., II, 8), com os criando conceitos (supostamente; o subjuntivo inuenisset sugere, como mais tarde se tornará manifesto, que Cícero não assume tal opinião), precisou se servir de termos novos.

Mas a verdade é que nem sempre há necessidade de termos novos. É o que se compreende a partir da crítica a tradutores que, pouco hábeis na arte de verter, traduzem palavra por palavra. ${ }^{23}$ Quando há a possibilidade, o tradutor deve se servir de uma palavra mais usual em seu idioma, para verter um termo da outra língua, desde que a palavra da língua de chegada declare o mesmo. Quanto a "a declarar o mesmo", Cícero, aparentemente não problematiza. Nós por outro lado, tendo em vista a dificuldade, senão a impossibilidade de uma palavra, que participa do sistema de signos de determinada língua, declarar o mesmo que declarava outra palavra, de língua distinta e que, naquela língua, ocupava uma posição singular em relação a todas as demais palavras que compõem o léxico, não podemos deixar de observar que a tradução filosófica aqui proposta faz a expressão se apegar mais fortemente à língua de chegada, ao seu sistema de signos, cujos valores são constituídos pelo uso. Para o tradutor disertus - digamos -, mais importante do que verter ao pé da letra, forjando novos termos, promovendo decalques latinos a partir de termos gregos, é encontrar correspondentes latinos que permitam, mesmo que sob o risco de talvez trair certo traço idiossincrático do conceito original, expressar a ideia geral do que se discutia em grego. Mais que isso: expressar o modo como o uso da língua romana interpreta aquilo que se via discutido em grego. Trata-se, então, de aproximar o debate filosófico do usus latino. Importa que o latim, que a cultura latina, assimile a filosofia por meio de seu próprio sistema simbólico. O propósito é tornar possível o debate filosófico entre os romanos em sua própria língua; ${ }^{24}$ um debate que se desenvolva em meio ao acervo cultural próprio dos romanos. A tradução se submete ao uso e, de modo mais amplo, ao projeto ciceroniano de constituição de uma filosofia que promova a educação do homem público... romano.

$\mathrm{E}$ a teoria encontra respaldo na prática. $\mathrm{O}$ autor aplica esse tipo de procedimento ao utilizar termos como honestum, officium, uisum, decorum, probabile 25 e muitos outros. Isso cria uma tendência, na prosa filosófica ciceroniana, de tornar 
a filosofia, mesmo que sendo arte dotada de um jargão, mais próxima da linguagem comum das pessoas letradas. Há, sem dúvida, na defesa desse tipo de tradução, certa aversão ao jargão técnico filosófico, algo que, evidentemente, repercutirá na crítica que será feita ao estoicismo.

O procedimento apresentado a seguir no trecho citado (III, 15-16) pode ser interpretado de duas maneiras. Poderia indicar o uso de uma perífrase para exprimir aquilo que em grego vinha expresso por uma só palavra. Ora, também esse modo se ajusta ao projeto educacional ciceroniano: trata-se de uma tradução que é, ao mesmo tempo, uma explicação, e de que nosso autor se serve em casos como disserendi ratio ou philosophiae pars, quae est

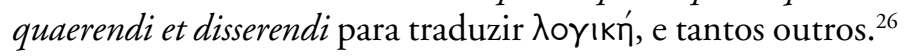
Por outro lado, poderíamos pensar que Cícero se refere ao procedimento de oferecer diversos sinônimos para traduzir um só termo grego, coisa que ocorre quando ele manifesta como que uma hesitação acerca da melhor opção para traduzir, ou então uma tentativa de tornar o conceito mais acessível por meio de um acúmulo de traduçôes. É o caso de finis, ultimum, extremum no prefácio de nossa obra. ${ }^{27}$

Por fim, ele defende que o tradutor se sirva, às vezes, de empréstimos gregos, quando não houver um correspondente próximo em latim. É o caso, por exemplo, de termos que nomeiem objetos do universo cultural grego, antes desconhecidos, mas agora presentes no mundo

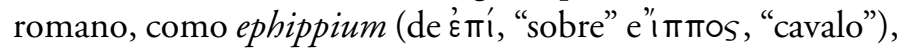
uma sela para cavalos, ou acratoforum (de ơkpatos, "nao

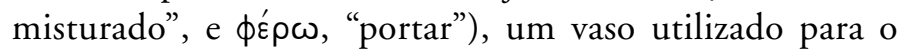
vinho puro. ${ }^{28}$ Esse modo de proceder é análogo ao dos antigos, que, no passado, tomaram do grego palavras como philosophia, grammatica, musica (cf. De fin., III, 5), e outras tantas, que designavam realidades desconhecidas dos romanos. Consagradas pelo uso, passaram a fazer parte do léxico latino.

Não deixa de ser interessante, então, o comentário de Cícero aos termos proegmena e apoproegmena, que, por supostamente não contarem com termos latinos correspondentes, seriam aceitáveis em grego mesmo. Apesar da consideração, a personagem faz questão de vertê-los, como que de improviso. Parece uma forma de demonstrar o vigor interlocutores sentados. A mudança de cenário e de postura das personagens parece também se ajustar ao andamento da discussão: à exposição mais relaxada de Quinto se contrapõe a refutação mais cerrada de Cícero.

17. Note-se como a ressalva feita por Cícero sublinha a necessidade do otium para que se torne aceitável, para um dos líderes da cidade, a leitura desvinculada da atividade política e, evidentemente, o estudo da filosofia.

18. De finibus bonorum et malorum libri quinque. With introduction and commentary by W. M. L. Hutchinson. London: Edward Arnold, 1909.

19. É espirituoso o argumento, pois a crítica não deixa de conter certo elemento de louvor, por mais paradoxal que isso possa parecer. Como já apontamos, Cícero defende que a filosofia é fundamental para a formação do homem público - ora o Orator deixa isso muito claro em muitas passagens, mas especialmente na introdução. E Catão, ávido, lendo mesmo antes das sessóes, parece ser um exemplo do tipo de político que Cícero pretende formar. Em nossa argumentação, preferimos ressaltar o elemento negativo, digamos, do tratamento dado à personagem, sobretudo porque pretendemos mostrar como o autor parece se servir disso na refutação que atribui à personagem que leva seu próprio nome. 
20. Literalmente, exprimi uerbum e uerbo: "fazer sair de uma palavra uma outra palavra", isto é, parece-nos, "decalcar a partir do grego o termo em latim", ou, por outro lado, "pretender dar a cada palavra o seu correspondente perfeito".

21. Indisertus se diz desse tipo de tradutor. Entendemos como aquele que não é versado numa arte da tradução. Poder-se-ia discutir se Cícero apresenta de fato uma ars definida, o fato é que discute teoricamente a tradução nesta passagem justamente.

Defende, além disso, uma tradução que se ajusta a seu projeto educacional. Recordemos, ademais, que no Orator, por exemplo, o orador disertus é aquele que aprendeu os preceitos das Artes, mas que não tem formação em filosofia (cf.

Orator, 13: ita et doctis eloquentia popularis et disertis elegans doctrina defuit).

22. De fin., III, 15-16: Experiamur igitur, inquit, etsi habet haec Stoicorum ratio difficilius quiddam et obscurius. nam cum in Graeco sermone haec ipsa quondam rerum nomina nouarum non uidebantur, quae nunc consuetudo diuturna triuit; quid censes in Latino fore?

Facillimum id quidem est, inquam. si enim Zenoni licuit, cum rem aliquam inuenisset inusitatam, inauditum quoque ei rei nomen inponere, cur non liceat Catoni? nec tamen exprimi nerbum e uerbo necesse erit, ut interpretes indiserti solent, cum sit uerbum, quod idem declaret, magis usitatum. da língua latina, coisa que amiúde ele defende. É como se dissesse: por vezes, o que aparentemente não encontra nenhum correspondente em latim, pode ser vertido afinal. Comparece como um munus na obra de Cícero, geralmente em tom de rivalidade com os gregos, a exortação ao empenho dos escritores romanos, com vistas à expansão das litterae latinae; por outro lado, a inclusão dessas traduções, feitas como que de improviso, permite-lhe assinar a autoria desses termos que, acolhidos prontamente por Catão, vão servir à exposição.

Já no livro IV, quando procede à refutação, Cícero desenvolve o argumento que avançara de início: Zenão e os demais estoicos admitiram o sistema moral da Antiga Academia (à qual Cícero associa ainda a escola de Aristóteles), mas promoveram uma reelaboração terminológica, a qual, vale dizer, era desnecessária:

Há alguns pontos obscuros - diz Catão -, eu admito, todavia eles não se expressam assim de propósito, é inerente às próprias coisas a obscuridade.

Por que é, então - retomei - que ao dizerem as mesas coisas os peripatéticos, não há uma só palavra que não se entenda? ${ }^{29}$

Essa defesa de uma continuidade de pensamento entre a chamada Antiga Academia e o Pórtico é, como sabemos, a marca de um filósofo influente no pensamento ciceroniano: Antíoco de Áscalon. Se Catão reluta em aceitar o argumento de Cícero, boa parte do livro IV será dedicada a demonstrar que os estoicos se servem mal da linguagem em suas exposiçōes. Cícero indica o motivo: eles negligenciaram parte do estudo da expressão verbal.

Esse gênero de estudos, ${ }^{30}$ em sua totalidade, Zenão e os que vieram depois dele ou não foram capazes de conservá-lo ou não o quiseram; o certo é que o deixaram de lado. Ainda que Cleantes tenha escrito uma Arte Retórica, e até mesmo Crisipo, escreveram de um modo que, se alguém desejasse quedar mudo, não deveria ler outra coisa. Assim, tu vês de que modo eles se expressam: forjam palavras novas e abandonam as usuais. ${ }^{31}$ 
E mais abaixo:

Suas pequenas interrogações, pontiagudas, picam como se fossem ferrōes; ${ }^{32}$ mas mesmo os que a elas dão assentimento em nada mudam suas almas e vão embora idênticos a como chegaram. Pois coisas que talvez sejam verdadeiras, certamente importantes, não são tratadas com se deve, mas de um modo, talvez, muito truncado. ${ }^{33}$

Pois bem, negligenciando parte do estudo da expressão verbal (Cícero aponta precisamente que foi deixada de lado a tópica), os estoicos, na tentativa de corrigir o sistema dos acadêmicos antigos, teriam criado uma linguagem extremamente apartada da linguagem usual, apartada mesmo do jargão filosófico já estabelecido. Apegados aos termos e não às coisas, transformaram pensamentos persuasivos em fórmulas pouco dignas de fé. Operaram uma mudança de vocabulário, desnecessária, dentro da mesma língua. Tornaram-se inacessíveis e, assim, incapazes de tocar o ouvinte de modo a fazê-lo mudar de opinião. Promovendo uma desnecessária correção vocabular, tornaram-se incapazes de corrigir os mores, os modos de vida. A falha na expressão produz uma falha na reflexão moral.

O mais grave e fundamental equívoco estoico, no que diz respeito ao estudo do sumo bem, diz Cícero, está na própria consideração do que seja o bem e do que seja o mal. $\mathrm{O}$ autor ironiza a pretensão dos estoicos de corrigir o pensamento dos antigos. Dessa pretensão surgiu a terminologia defeituosa, coisa que a personagem Cícero aponta na passagem a seguir, com saborosa ironia.

Eles dirão ser outros, creio eu, os grandes erros dos antigos, que ele, desejoso de seguir o rastro da verdade, não pode de modo algum suportar. Mas que contrassenso maior existe, o que é mais insustentável, o que é mais insensato do que serem colocados entre os bens a boa saúde, a ausência de todas as dores, a integridade dos olhos e dos demais sentidos? Deveriam dizer, isso sim, que não há absolutamente nenhuma diferença entre essas coisas e as que lhes são contrárias? Pois tudo aquilo que eles diriam serem bens, Zenão disse serem preferíveis; ${ }^{34} \mathrm{e}$, do mesmo modo, aquilo que no corpo seria superior os antigos afirmaram, de modo equidem soleo etiam quod uno Graeci, si aliter non possum, idem pluribus uerbis exponere. et tamen puto concedi nobis oportere ut Graeco uerbo utamur, si quando minus occurret Latinum, ne hoc ephippiis et acratophoris potius quam proëgmenis et apoprö̈gmenis concedatur; quamquam haec quidem praeposita recte et reiecta dicere licebit. Bene facis, inquit, quod me adiuuas, et istis quidem, quae modo dixisti, utar potius Latinis, in ceteris subuenies, si me haerentem uidebis.

23. Note-se que no livro I, a expressão ad uerbum, que interpretamos como "literalmente" (cf. De fin., I, 4), refere-se à adaptação, feita por poetas, de peças de teatro gregas. Ali, segundo pensamos, a expressão é usada enfaticamente e em um contexto em que o autor pretende distanciar a sua composição filosófica - que seria mais livre - das adaptações teatrais que já ocorriam em língua latina, cf. Powell, 1995, p. 277. Daí ele poder considerar que uma adaptação de peça de teatro possa ser uma tradução literal, sobretudo se comparada a sua empresa filosófica, que, embora possa se servir de empréstimos, não será uma mera tradução.

24. Veja-se, nesse sentido, a argumentação de Auvray-Assayas em Cicéron, p. 29-41.

25. Para traduzir tò kalón, tò kathékon, phantasia, tò prêpon, e tò pithanón respectivamente. Quanto a honestum, ver, em especial, De fin., II, 48. 
26. Cf. Powell, 1995,

27. Sobre esse tipo de procedimento, veja-se ainda De fin., III, 26.

"Uma vez que o termo extremo - com efeito, tu percebes, creio eu, que eu

já há muito tempo denomino ora extremo, ora último, ora sumo o que os gregos denominam Tદ́入os, sera possível, ainda, dizer 'fim' em lugar de extremo ou último -..." / cum enim hoc sit extremum - sentis enim, credo, me iam diu,

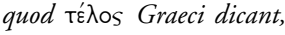
id dicere tum extremum, tum ultimum, tum summum; licebit etiam finem pro extremo aut ultimo dicere -...

28. Note-se que o uso desse tipo de palavras é aceitável até mesmo na prosa oratória - que é claramente voltada para um público mais amplo em casos como os dos discursos contra Verres, em que os termos que se referem a objetos de arte gregos são abundantes (cf. Albrecht, 2003, p.18).

29. De fin., IV, 2: Obscura, inquit, quaedam esse confiteor, nec tamen ab illis ita dicuntur de industria, sed inest in rebus ipsis obscuritas.

Cur igitur easdem res, inquam, Peripateticis dicentibus uerbum nullum est, quod non intellegatur?

30. Isto é, o estudo da expressão verbal como um todo. A personagem de Cícero fizera uma distinção, que comparece aliás em outras obras suas, entre duas espécies de controvérsia: a geral e a insensato, que deveria ser buscado por si mesmo; Seria melhor ter dito acolhido do que buscado. ${ }^{35}$

A questão da linguagem é, como vemos, central no diálogo estoico. Diante do que Cícero parece entender por filosofia, isto é, um modo de refletir sobre as questôes mais importantes que pode ajudar os homens na administração de suas comunidades, o vício dos estoicos cria um sistema que, mesmo se correto, de um modo geral, não consegue comunicar suas conclusões, suas verdades às pessoas em geral. Trata-se de um sistema que defende com vigor o caráter absoluto da virtude, mas que, no entanto, não tem serventia na cidade:

O patrono de uma causa, no epílogo, discursando em favor do réu, diria que não é um mal o exílio, ou o confisco dos bens? Que são coisas a ser rejeitadas, mas não evitadas? E que o juiz não deve ser misericordioso? Ora, e se falasse em uma assembleia, caso Aníbal tivesse chegado às portas da cidade e a muralha com uma lança ultrapassasse, ${ }^{36}$ ele diria que não se contam entre os males tornar-se cativo, ser vendido, ser assassinado, perder a pátria? (...) Mas que filosofia é essa, então, que fala no fórum segundo o costume comum e, nos tratados, segundo um costume que é só seu? Sobretudo uma vez que naquilo que eles dão a entender com suas palavras não haja nenhuma inovação, mas persistam as mesmas coisas, expressas de outro modo? Pois que diferença há entre dizeres que as riquezas, o poder, a saúde são bens e dizeres que são coisas preferíveis, uma vez que aquele que as chama bens não lhes atribua nada mais do que tu, que denominas as mesmas coisas preferíveis ${ }^{37}$

Sabemos que Cícero, por sua vez, não dissocia completamente filosofia e eloquência. Ele as antes considera aliadas uma da outra. ${ }^{38}$ Há um interessante passo em que sua personagem interpreta a vida intelectual de Zenão recorrendo a preconceitos bem romanos, com os quais ele intenta dirimir a auctoritas do fundador do estoicismo. $\mathrm{O}$ contexto contém um argumento mais minucioso, é verdade, que deve ser elucidado. Cícero acaba de defender que o movimento, sustentando pelos estoicos, desde a primeira tendência (ópuń) ate o sumo bem, se faz de modo incorreto, pelo fato de eles desconsiderarem uma parte fundamental 
da natureza humana: o corpo. A virtude, o sumo bem, refletiria apenas a pulsão anímica. Daí que tudo o que não fosse a virtude se tornasse indiferente quanto ao sumo bem. Para Cícero, Zenão teria mesmo reconhecido o erro, o que, claro, não passa de uma suposição maliciosa e muito bem empregada na estratégia argumentativa:

Em seguida, teu pequeno cartaginês - pois tu sabes que os citienses, teus clientes, provêm da Fenícia -, um homem agudo, portanto, não obtendo vitória em sua causa (a natureza resistia), pôs-se a revirar as palavras e, em primeiro lugar, àquelas coisas que nós chamamos bens ele concedeu serem consideradas "estimáveis" e "ajustadas à natureza”, e pôs-se a declarar que ao sábio, isto é, ao homem sumamente feliz, é todavia mais vantajoso que ele possua também aquelas coisas que ele não ousa denominar bens, mas que ele concede que são ajustadas à natureza. ${ }^{39}$

O chiste é mais saboroso se lido à luz de uma passagem do livro $\mathrm{V}$, em que a personagem Pisão, oferecendo um panorama acerca das soluções propostas para a questão do finis, compara a ação dos primeiros estoicos a de ladrôes que, para que pudessem guardar, impunes, o fruto do roubo, alteraram as marcas distintivas dos objetos roubados. No caso dos estoicos (e de Zenão, o fundador da escola), a alteração é dos termos, que são como que as marcas das coisas, dos conceitos roubados (De finibus, V, 74). ${ }^{40}$

Neste breve texto, que lidou, mesmo se de modo às vezes pouco detido, com alguns pontos importantes da refutação ciceroniana da moral estoica nos livro III e IV do De finibus, pretendemos chamar a atenção para algumas das estratégias de persuasão utilizadas pelo autor. $O$ fio condutor da disputatio, que é tão habilmente representada do ponto de vista dramático, é a crítica da expressão filosófica dos estoicos. Querendo corrigir a filosofia dos antigos, eles teriam criado, já em grego mesmo, uma linguagem apartada do uso, pouco acessível mesmo para os versados em filosofia. É, sob esse aspecto, um modo de filosofar diametralmente oposto ao defendido por Cícero, o qual, por sua vez, parece tão bem ilustrado em sua reflexão acerca da tradução. $\mathrm{Na}$ representação mimética, o filósofo estoico encontra um representante significativo: Catão. É moralmente notável, circunstancial. Vale dizer que, nessa passagem, a retórica vem tratada como uma parte da política.

31. De fin., IV, 7: Totum genus hoc Zeno et qui ab eo sunt aut non potuerunt $<$ tueri $>$ aut noluerunt, certe reliquerunt. quamquam scripsit artem rhetoricam Cleanthes, Chrysippus etiam, sed sic, ut, si quis obmutescere concupierit, nibil aliud legere debeat. itaque uides, quo modo loquantur. noua uerba fingunt, deserunt usitata.

32. As interrogatiunculae são os silogismos, que, na tradição estoica, tomam a forma de interrogaçóes.

33. De fin., IV, 7:

Pungunt quasi aculeis interrogatiunculis angustis, quibus etiam qui assentiuntur nibil commutantur animo et idem abeunt, qui uenerant. res enim fortasse uerae, certe graues, non ita tractantur, ut debent, sed aliquanto minutius.

Aliquanto minutius pode ainda querer dizer "de modo muito apegado às minúcias" e "sem grande desenvolvimento, sem amplitude". As duas ideias, se pensarmos na teoria retórica de Cícero, não estão separadas.

34. Ver De fin., III, 1517 e 51-56.

35. De fin., IV, 20. Alia quaedam dicent, credo, magna antiquorum esse peccata, quae ille ueri inuestigandi cupidus nullo modo ferre potuerit. quid enim peruersius, quid intolerabilius, quid stultius quam bonam ualitudinem, quam dolorum omnium uacuitatem, quam 
integritatem oculorum reliquorumque sensuum ponere in bonis potius, quam dicerent nibil omnino inter eas res iisque contrarias interesse? ea enim omnia, quae illi bona dicerent, praeposita esse, non bona,

itemque illa, quae in corpore excellerent, stulte antiquos dixisse per se esse expetenda; sumenda potius quam expetenda.

36. Isto é, tivesse lançado uma lança através da muralha.

37. De finibus IV, 22-23: Patronusne causae in epilogo pro reo dicens negaret esse malum exilium, publicationem bonorum? haec reicienda esse, non fugienda? nec misericordem iudicem esse oportere? in contione autem si loqueretur,

si Hannibal ad portas uenisset murumque iaculo traiecisset, negaret esse in malis capi, uenire, interfici, patriam amittere? (...) quae est igitur ista philosophia, quae communi more in foro loquitur, in libellis suo? praesertim cum, quod illi suis uerbis significent, in eo nibil nouetur, [de ipsis rebus nibil mutetur] eaedem res maneant alio modo. quid enim interest, diuitias, opes, ualitudinem bona dicas anne praeposita, cum ille, qui ista bona dicit, nihilo plus iis tribuat quam tu, qui eadem illa praeposita nominas?

38. Essa ideia, que é defendida em tantas passagens de sua obra, é tratada por meio do termo societas (aliança, como a que fazem povos em uma guerra) em De fato, III. singular, reconhecido pelo leitor como mártir da República. Encontra-se envolto em livros, é leitor ávido, insaciável. É até mesmo divino... Com tudo o que o adjetivo possa trazer de perigoso. No âmbito da cidade, é alguém com um discurso recôndito que é quase intangível. Caso queira se fazer compreender, é forçado à incoerência interna: defender aquilo em que não acredita. No imaginário criado por nosso autor, é o senador absorto em sua leitura, mesmo na Cúria. Em seu caso particular, absorto apenas até o começo da sessão - tudo bem! - talvez por um apego irrefletido ao mos maiorum. Além disso, exercitou-se em retórica, algo inusitado para um estoico, mas parece guardar consigo uma forte tendência, imposta por seu modo de pensar, ao isolamento, tanto linguístico quanto político.

\section{REFERÊNCIAS BIBLIOGRÁFICAS}

ALBRECHT, M. Cicero's style: a synopsis. Leiden: Brill, 2003. ARISTOTELES. Ethica Nicomachea. Recognouit breuique adnotatione critica instruxit L. Bywater. Oxford: Oxford Uiversity Press, 1894.

Ética a Nicômaco. Tradução de Leonel Vallandro e Gerd Bornheim da versão inglesa de W. D. Ross. In: Aristóteles II. São Paulo: Nova Cultural, 1987 (col. Os Pensadores).

AUVRAY-ASSAYAS, C. Cicéron. Paris: Société d'Édition "Les Belles Lettres", 2006.

CICÉRON. L'orateur / Du meilleur genre d'orateurs. Texte établi et traduit par Albert Yon. Paris: Société d'Édition "Les Belles Lettres", 1964.

De diuinatione. With an English translation by W. A. Falconer. London: Harvard University Press, 1992 (Loeb Classical Library).

De finibus bonorum et malorum. Recognouit breuique adnotatione critica instruxit L. D. Reynolds. Oxford: Oxford University Press, 1998. 
CICERO. De finibus bonorum je malorum libri quinque. With introduction and commentary by W.M.L. Hutchinson. London: Edward Arnold, 1909.

De l'orateur. Texte établi et traduit par Edmond Courbaud. Paris: Société d'Édition "Les Belles Lettres", 1957.

De natura deorum / Academica. With an English translation by H. Rackham. London : Harvard University Press, 1979 (Loeb Classical Library).

Des termes extrêmes des biens et des maux. Texte établi et traduit par Jules Martha. Paris : Société d'Édition "Les Belles Lettres", 1967.

. Epistulae ad Atticum. Edited by D. R. Shackleton Bailey. Stuttgart: Teubner, 1987. 2v.

. Epistulae ad jettersyss. Edited by D. R. Shackleton Bailey. Cambridge: CUP, 1977. 2v.

. Epistulae ad Quintum Fratrem ÿe M. Brutum. Edited by D. R. Shackleton Bailey. Cambridge : CUP, 1980.

On the ideal orator. Translated with introduction, notes, appendixes, glossary and indexes by James M. May and Jakob Wisse. Oxford: Oxford University Press, 2001.

GRIFFIN, M. "The composition of the Academica: motives and versions". In: Assent \& Argument. Studies in Cicero's Academic books. Edited by Brad Inwood \& Jaap Mansfeld. Leiden, New York: Brill, 1997a. p. 1-35.

LÉVY, Carlos. "Cicéron créateur du vocabulaire latin de la connaissance : essai de synthèse". In : la langue latine, langue de la philosophie. Actes du colloque organisé par l'Ecole française de Rome avec le concours de l'Université de Rome "La Sapienza" (Rome 17-19 mai 1990), 1992, p. 91-106.

LIMA, S. C. Aspectos do gênero dialógico no De finibus de Cícero. Tese de Doutorado. IEL/UNICAMP, 2009.

"Cícero e a obra filosófica em latim como jette rei publicae”. Nuntius Antiquus, v. V, jul. 2010, p. 92-110.

LISCU, Marin.O. "Etude de la langue de la philosophie morale chez Cicéron”. Paris: Les belles ÿetters, 1930.
39. De fin., IV, 56: Postea tuus ille Poenulus - scis enim Citieos, clientes tuos, e Phoenica profectos -, homo igitur acutus, causam non optinens repugnante natura uerba uersare coepit et primum rebus iis, quas nos bonas ducimus, concessit, ut haberentur aestimabiles et ad naturam accommodatae, faterique coepit sapienti, hoc est summe beato, commodius tamen esse si ea quoque habeat, quae bona non audet appellare, naturae accommodata esse concedit.

40. De fin., V, 74: "Restam os estoicos. Mas esses, não foi uma ou outra parte que de nós eles tomaram, mas toda a nossa filosofia transladaram à sua escola; e assim como os demais ladrōes alteram os traços distintivos das coisas que tomaram, da mesma forma eles, para que se servissem de nossos pensamentos como se fossem seus, os nomes, que são como que as marcas das coisas, eles alteraram". I Stoici restant. Ei quidem non unam aliquam aut alteram $<$ rem $>$ a nobis, sed totam ad se nostram philosophiam transtulerunt; atque ut reliqui fures earum rerum, quas ceperunt, signa commutant, sic illi, ut sententiis nostris pro suis uterentur, nomina tamquam rerum notas mutauerunt. 
PLATO. Gorgias. A revised text with introduction and commentary by E.R. DODDS. Oxford: Clarendon, 1990.

PONCELET, R. Cicéron traducteur de Platon. Paris: E. De Boccard, 1957.

POWELL, J. G. F. "Cicero's translations from Greek". In: Cicero the philosopher / Twelve papers. Edited and introduced by J. G. Powell. New York: Clarendon, 1995. P. 273-300.

RUCH, M. Le préambule dans les oeuvres philosophiques de Cicéron. Paris: Société d'Éditions "Les Belles Lettres", 1958.

WRIGHT, M.R. Cicero: on Stoic good and evil. Warminster: Aris \& Phillips, 1991.

Recebido em maio de 2014 Aprovado em agosto de 2014 